\title{
PM0 Stage Finding
}

National Cancer Institute

\section{Source}

National Cancer Institute. pMo Stage Finding. NCI Thesaurus. Code C48740.

No morphologic evidence of distant metastasis, in accordance with TNM classification system guidelines. 